E3S Web of Conferences 1, 03007 (2013)

DOI: $10.1051 / \mathrm{e} 3 \operatorname{sconf} / 20130103007$

(C) Owned by the authors, published by EDP Sciences, 2013

\title{
Spatial Patterns in Wet and Dry Deposition of Atmospheric Mercury to Illinois Watersheds
}

\author{
M. M. Lynam ${ }^{1}$, N. L. Hall ${ }^{2}$ and J. T. Dvonch ${ }^{3}$ \\ ${ }^{1}$ University of Michigan Air Quality Laboratory, Ann Arbor, MI 48109, USA, lynam@umich.edu \\ ${ }^{2}$ University of Michigan Air Quality Laboratory, Ann Arbor, MI 48109, USA, hallnai@umich.edu \\ ${ }^{3}$ University of Michigan Air Quality Laboratory, Ann Arbor, MI 48109, USA, dvonch@umich.edu
}

\begin{abstract}
An intensive one month atmospheric mercury monitoring campaign was carried out at 8 sites in central Illinois, USA, during summer of 2011 to assess spatial patterns in wet and dry deposition. Daily precipitation samples, turf surrogate surfaces, and throughfall samples were collected concurrently to measure both wet and dry deposition of mercury, trace metals and major ions. Average deposition values observed for the study period (June 9 to July 3, 2011) for total wet deposition and total dry deposition were $4.0 \pm 0.8 \mu \mathrm{g} / \mathrm{m}^{2}$ and $1.2 \pm 0.4 \mu \mathrm{g} / \mathrm{m}^{2}$, respectively. Based on previous findings, the summer 2011 wet deposition rates were higher compared to summers of 2008 and 2009 at the Nilwood and Peoria sites, and wet deposition during this period represented $20-30 \%$ of the annual deposition previously measured. Dry deposition ranged from 17 $-31 \%$ of total deposition across sites during the study period. Nilwood and its surrounding monitoring sites had slightly higher wet deposition compared to the more northerly Peoria and surrounding sites.
\end{abstract}

Key words: Mercury, trace elements, wet deposition, dry deposition

\section{Introduction}

Although total mercury emissions to the atmosphere from anthropogenic sources in the Great Lakes states declined by approximately 50\% (US EPA, NEI, 2005) between 1990 and 2005, measurements from monitoring networks in the United States and Canada show that annual mercury wet deposition did not change significantly from 2002 to 2008 (Risch et al, 2012a). Wet deposition of mercury was highest in several states, including Illinois. Additionally, dry deposition studies of mercury to litterfall have shown that significant deposition to forested landscapes occurred with a magnitude similar or greater than wet deposition and accounted for 25 to $69 \%$ of total deposition (Risch et al, 2012b). Recent research shows that toxicological responses to $\mathrm{Hg}$ in fish and wildlife are occurring at significantly lower concentrations than previously reported (Dillon et al, 2010, Sandheinrich et al, 2012). Illinois currently has a state-wide fish consumption advisory for all fresh waters due to elevated methylmercury concentrations in fish taken from these waters. Therefore, accurate assessment of inputs from wet and dry $\mathrm{Hg}$ deposition from the atmosphere is imperative to minimize impairment to fresh waters in the state.

Monitoring of $\mathrm{Hg}$ wet deposition at Bondville, IL has been ongoing since 1999. A recent multi-year wet deposition study collected event-based precipitation at four monitoring locations in Illinois and revealed background total $\mathrm{Hg}$ concentrations ranging from 3.8 $4.7 \mathrm{ng} / \mathrm{L}$ (Gratz, 2010). These concentrations were similar in magnitude to those measured in $\mathrm{MI}$ and $\mathrm{OH}$ (White et al, 2009) and are consistent with impacts from local and urban/industrial sources. In particular, the measurements revealed the highest volume weighted mean concentrations of $\mathrm{Hg}$ in precipitation and total $\mathrm{Hg}$ deposition during the spring/summer months at three out of the four sites. These previous measurements did not include attempts to assess contributions from $\mathrm{Hg}$ dry deposition.

To supplement previous monitoring efforts in Illinois, an intensive one-month monitoring campaign was conducted with the following objectives;

(i) Collection of daily $\mathrm{Hg}$ wet and dry deposition samples at previously monitored Nilwood and Peoria, IL sites during summer, and at three additional satellite locations surrounding the Nilwood and Peoria sites.

(ii) Evaluation and characterization of spatial patterns and variability surrounding each network site. 


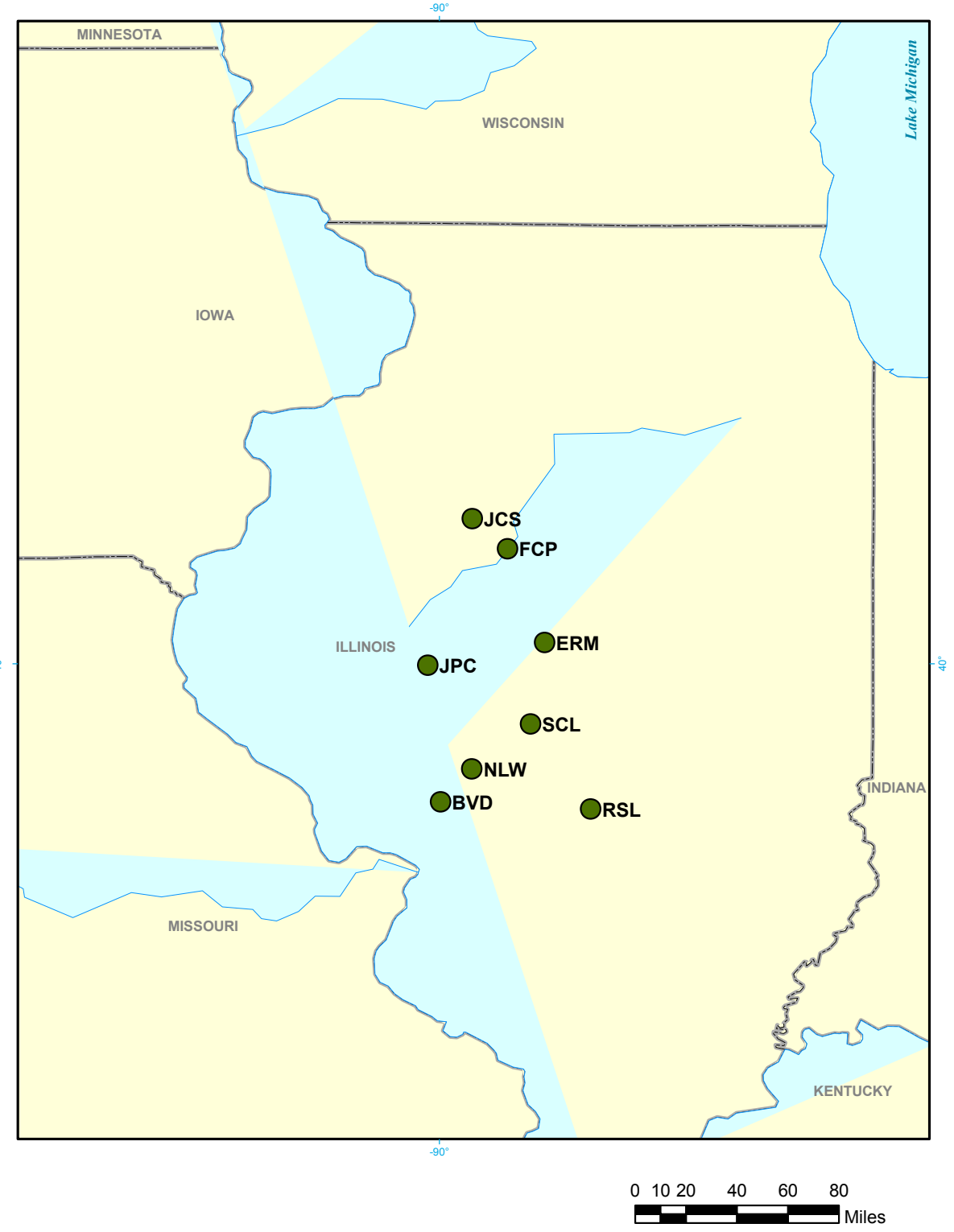

Fig. 1. Location of wet and dry deposition sampling sites in Illinois.

(iii) Greater understanding of the contributions of wet versus dry deposition of $\mathrm{Hg}$ and the spatial influence of emission sources.

Long and short term monitoring of wet and dry deposition of $\mathrm{Hg}$ is essential in establishing baseline conditions especially since the US EPA has recently issued the Mercury and Air Toxics Standards (MATS) rule for utility boilers (US EPA, 2011). This rule aims to limit emissions of mercury and other toxic pollutant emissions. Information generated from this intensive study can be used with future studies to assess whether future changes are as a result of controls implemented under the MATS rule.

\section{Materials and Methods}

Daily precipitation samples for $\mathrm{Hg}$ and trace metals were collected at Nilwood, IL $(39.395,-89.810)$ and its satellite sites - Beaver Dam State Park, IL (39.209,
-89.988), Ramsey Lake State Park, IL (39.169, -89.135) and Sangchris Lake State Park, IL (39.653, -89.477). The Peoria site was located in Fort Crevecoeur State Park, IL $(40.649,-89.607)$ and its satellite sites were Edward R. Madigan State Park, IL (40.115, -89.396), Jim Edgar Panther Creek State Park, IL (39.986, -90.061) and Jubilee College State Park, IL (40.832, -89.808), Figure 1. All samples were collected from June $9^{\text {th }}$ though July $3^{\text {rd }}$, 2011. Dry deposition sampling was also carried out at these sites, over integrated sample periods of three-days in duration.

Field and analytical supplies used during sampling for mercury and trace metals were subjected to an acid-cleaning procedure prior to deployment in the field (Landis and Keeler, 2007). The sampling train deployed for $\mathrm{Hg}$ in precipitation comprised a borosilicate glass funnel (average sampling area of $183 \pm 5 \mathrm{~cm}^{2}$ ) coupled to a $1 \mathrm{~L}$ fluorinated polyethylene bottle by means of an 


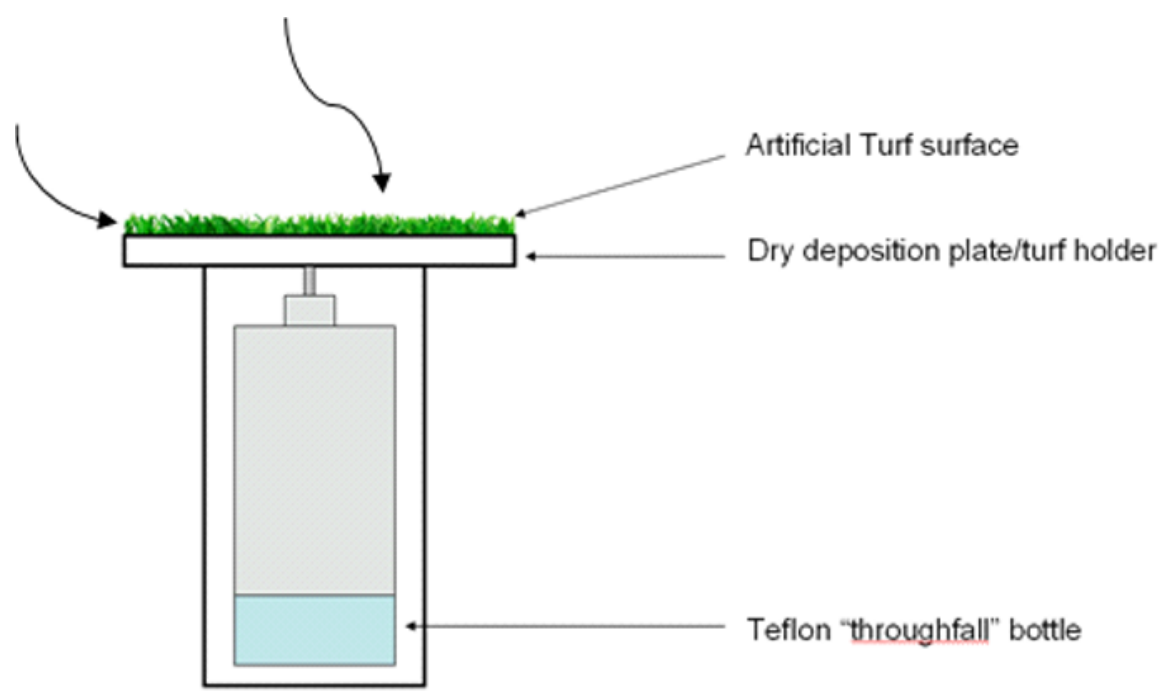

Fig. 2. Schematic of artificial turf surrogate surface deposition sampler.

adapter. The teflon adapter contained a glass vapor lock to minimize loss of vapor phase $\mathrm{Hg}$ during sampling. The sampling train deployed for trace metals in precipitation comprised a polypropylene funnel (average sampling area of $171 \mathrm{~cm}^{2}$ ) coupled to a $1 \mathrm{~L}$ polypropylene bottle by means of a polypropylene adapter. Dry deposition sampling was accomplished by using an artificial turf surrogate surface sampler shown in Figure 2. The sampling train comprised a disc of artificial turf of diameter $19.15 \mathrm{~cm}$ and an area of $258.4 \mathrm{~cm}^{2}$. The turf had approximately 1-inch high polyethylene grass-like blades and was placed into a well style insert in an aerodynamic air foil. The airfoil was coupled to a fluorinated polyethylene bottle which collected deposition throughfall. The turf surface sampler was deployed for a period of 72-hours while throughfall was collected daily and replaced with a new sample bottle to collect further throughfall. Upon receipt at the University of Michigan Air Quality Laboratory samples for $\mathrm{Hg}$ analysis were immediately oxidized in a class 100 clean room with bromine monochloride, $\mathrm{BrCl}, 1 \%(\mathrm{v} / \mathrm{v})$ for precipitation and throughfall and $4 \%(\mathrm{v} / \mathrm{v})$ for turf samples. $\mathrm{Hg}$ in turf samples was extracted by sonication in $350 \mathrm{mls} \mathrm{MQ}$ grade water for 2-3 hours. All Hg-containing samples were stored in a cold room for at least 24 hours prior to analysis by cold vapor atomic fluorescence spectroscopy, CVAFS. Trace metals samples with sufficient volume were subsampled by pouring off an aliquot of approximately $15 \mathrm{mls}$ for analysis of major ions by Ion Chromatography, IC. The remaining larger aliquot was acidified with concentrated $\mathrm{HNO}_{3}$ to a $1 \%$ solution $(\mathrm{v} / \mathrm{v})$ and stored for a minimum of two weeks in a cold room prior to analysis using magnetic sector inductively coupled mass spectrometry, ICP-MS.

\section{Results and Discussion}

Concentrations of $\mathrm{Hg}$ in precipitation, observed at the eight IL sites ranged from a minimum of 11.4 to a maximum of $69.4 \mathrm{ng} / \mathrm{L}, \mathrm{N}=64$, while average concentrations for all sites ranged from $24.8-40.0 \mathrm{ng} / \mathrm{L}$. Assuming a range of background $\mathrm{Hg}$ precipitation concentrations of 3-5 ng/L (White et al, 2009) these event based samples indicate that for the period under study concentrations in precipitation at all sites were elevated. These results are consistent with previous findings at sites in IL where concentrations greater than $25 \mathrm{ng} / \mathrm{L}$ were observed most frequently during the warm summer months (UMAQL, 2010). This is likely due to a combination of meteorological, source emission and atmospheric chemistry factors that are present. Figure 3 is a plot of total wet and total dry deposition for the study period at each site in IL. All sites received higher levels of wet deposition as compared to dry deposition during the period of study. On average, total wet deposition at the sites with a more southerly location received higher amounts of wet deposition, $4.6 \mu \mathrm{g} / \mathrm{m}^{2}$ (NLW and satellites) vs $3.5 \mathrm{\mu g} / \mathrm{m}^{2}$ (FCP and satellites). Monthly wet deposition in 2008 and 2009 at Nilwood was 2.5 and $2.7 \mu \mathrm{g} / \mathrm{m}^{2}$, and $2.5 \mu \mathrm{g} / \mathrm{m}^{2}$ and $2.2 \mu \mathrm{g} / \mathrm{m}^{2}$, respectively (Gratz, 2010).

There was less of a gradient observed for total dry deposition for all sites with average values of $1.3 \mu \mathrm{g} / \mathrm{m}^{2}$ (NLW and satellites) and $1.2 \mu \mathrm{g} / \mathrm{m}^{2}$ (FCP and satellites). Ratios of dry deposition to total deposition (wet plus dry) ranged from $17-31 \%$ during the study period. Measurements at Nilwood and Peoria, IL for the calendar year 2008 showed annual wet deposition of $16.5 \mu \mathrm{g} / \mathrm{m}^{2}$ and $14.8 \mu \mathrm{g} / \mathrm{m}^{2}$ at these sites (Gratz, 2010). Increased spatial monitoring in the vicinities of the Nilwood and Peoria sites during this study confirms that central IL receives a significant portion of wet and dry deposition during the warm months. 


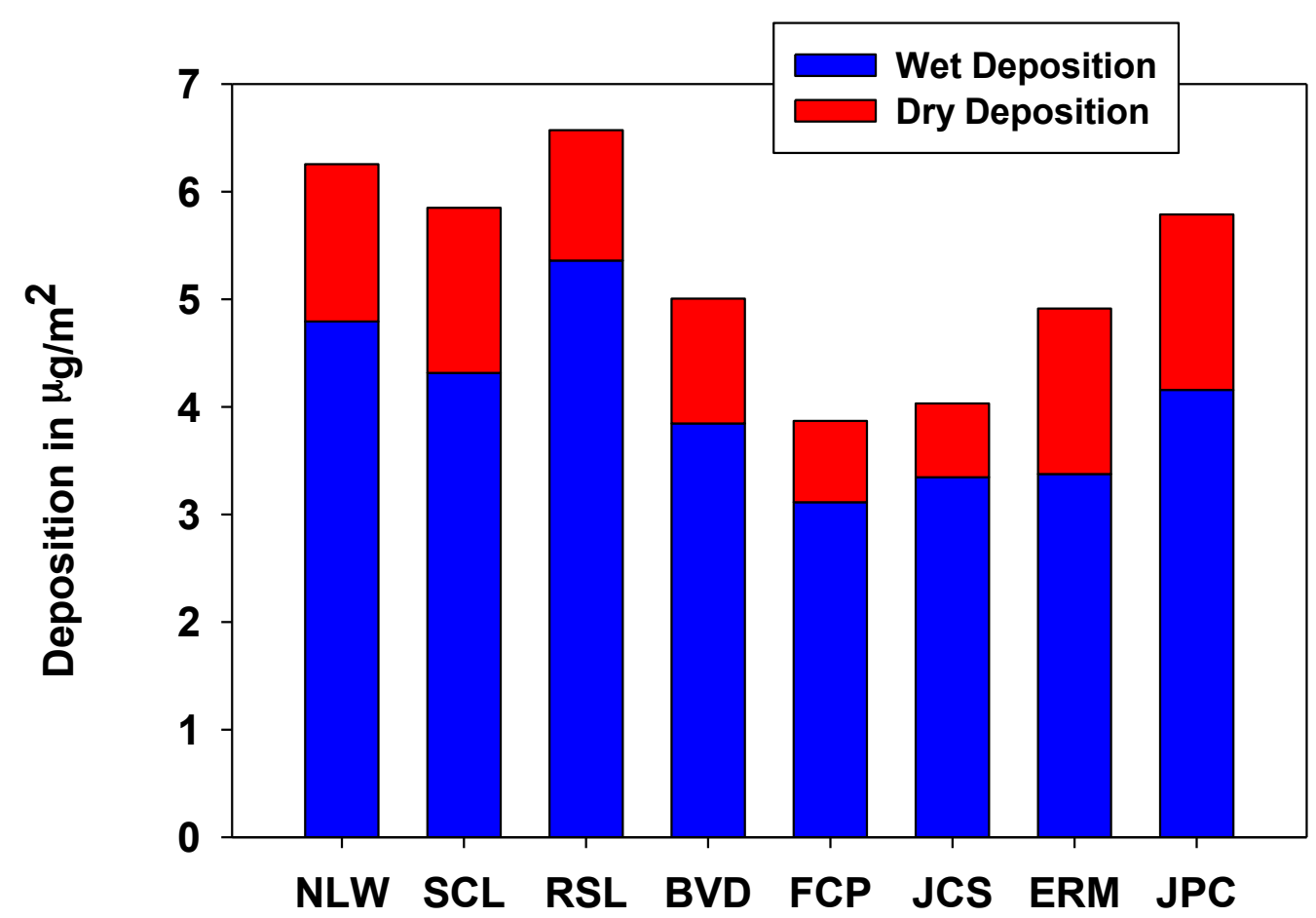

Fig. 3. Observed mercury deposition at study sites inIllinois from Jun 9 -Jul 3, 2011.

\section{Conclusion}

Based on outcomes from previous studies, increased spatial monitoring of wet deposition with the addition of monitoring for previously uncharacterized dry deposition was carried out in central Illinois in June 2011. Significant amounts of wet and dry deposition were observed at all eight sites. In particular, for wet deposition, more southerly sites received higher amounts of wet deposition. Based on previous measurements of wet deposition at the Nilwood and Peoria sites, the present study shows that as much as $20-30 \%$ of annual wet deposition of $\mathrm{Hg}$ was received at both sites during the 25 days of this study period.

\section{Acknowledgements}

Funding for this project was provided by the State of Illinois Environmental Protection Agency Bureau of Water.

\section{References}

Dillon T, Beckvar S, Kern J. Residue-based dose-response in fish: an analysis using lethality-equivalent endpoints. Environmental Toxicology and Chemistry 2010, 29:2559-2565.

Gratz LE, Identification of atmospheric mercury sources and transport pathways on local and regional scales. $\mathrm{Ph}$. D. thesis, University of Michigan 2010.

Landis MS, Keeler GJ. Critical evaluation of a modified automatic wet-only precipitation collector for mercury and trace element determinations. Environmental Science and Technology 1997, 31:2610-2615.

Risch MR, Gay DA, Fowler KK, Keeler GJ, Backus SM, Blanchard P, Barres JA, Dvonch JT. Spatial patterns and temporal trends in mercury concentrations, precipitation depths, and mercury wet deposition in the North American Great Lakes region. Environmental Pollution 2012, 161:261-271.

Risch MR, DeWild JF, Krabbenhoft DP, Kolka RK, Zhang L. Litterfall mercury dry deposition in the eastern USA. Environmental Pollution 2012, 161:284-290.

Sandheinrich MB, Bhavsar SP, Bodaly RA, Drevnick PE, Paul EA. Ecological risk of metyhylmercury to piscivorous fish of the Great Lakes region. Ecotoxicology 2012, 20:1577-1587.

U.S. EPA 2011, Mercury and Air Toxics Standards for Power Plants, http://www.epa.gov/mats/actions.html retrieved April, 2012.

U.S. EPA National Emissions Inventory (NEI) Air Pollutant Emissions Trends Data, http://www.epa.gov/ttnchie1/trends/ retrieved April, 2012.

University of Michigan Air Quality Laboratory (UMAQL), Assessing the risk of mercury deposition to Illinois watersheds from coal-fired utilities and other major sources. Report prepared for the State of Illinois Department of 
Environmental Protection Bureau of Water, June 2010.

White EM, Keeler GJ, Landis MS. Spatial variability of wet mercury deposition in eastern Ohio: summertime meteorological case study analysis of local source influences. Environmental Science and Technology 2009, 43:4946-4953. 